\title{
Repeat Single Incision Laparoscopic Surgery after Primary Single Incision Laparoscopic Surgery for Colorectal Disease
}

\author{
Sun Hye Kim, M.D., Seong Hyeon Yun, M.D., Ph.D., Yoon Ah Park, M.D., Yong Beom Cho, M.D., Ph.D., \\ Hee Cheol Kim, M.D., Ph.D., Woo Yong Lee, M.D., Ph.D. \\ Department of Surgery, Samsung Medical Center, Sungkyunkwan University School of Medicine, Seoul, Korea
}

Purpose: Single-incision laparoscopic surgery (SILS) for colorectal surgery is widely performed for many disease entities. However, there are few reports about the role of repeat single-incision laparoscopic surgery (R-SILS). The aim of this study is to analyze R-SILS data to evaluate the feasibility and safety of the occurrence and review its outcomes.

Methods: This is a retrospective review of the prospectively collected SILS database in Samsung Medical Center, Seoul, Korea, between April 2009 and December 2015. A retrospective review of 38 patients who underwent R-SILS from 2,207 patients who underwent primary SILS for colorectal surgery was performed.

Results: The indications of R-SILS were 23 primary SILS-related complications, 10 cancer-related, and 5 other surgical indications. Of the 38 repeat surgeries, 24 were emergent operations, and 14 were elective operations. Fecal diversion for anastomotic leakage after rectal surgery was the most common reason for reoperation. There were 2 cases of conversions: one case was converted to conventional multi-port, and the other case was converted to open surgery. Mean operative time was 137.9 $\pm 64.1 \mathrm{~min}$, estimated blood loss (EBL) was $105 \pm 98 \mathrm{ml}$, and length of hospital stay was $10.1 \pm 8.1$ days. Post-operative complication was noted in 5 (13.2\%) of 38 R-SILS cases, and there was no 30-day postoperative mortality.

Conclusion: Repeat single-incision laparoscopy surgery is feasible and safe in select patients when performed by an experienced surgeon.

Keywords: Minimally invasive surgical procedures, Single-incision laparoscopic surgery, Repeat operation, Colorectal surgery

This is an Open Access article distributed under the terms of the Creative Commons Attribution Non-Commercial License (http:// creativecommons.org/licenses/by-nc/4.0/) which permits unrestricted non-commercial use, distribution, and reproduction in any medium, provided the original work is properly cited.
Received September 7, 2017

Revised 1st October 24, 2017

2nd December 3, 2017

Accepted December 7, 2017

Corresponding author

Seong Hyeon Yun

Department of Surgery, Samsung

Medical Center, Sungkyunkwan

University School of Medicine, 81

Irwon-ro, Gangnam-gu, Seoul

06351, Korea

Tel: +82-2-3410-6546

Fax: +82-2-3410-6980

E-mail: shyunmd@gmail.com

ORCID:

http://orcid.org/0000-0003-3913-1481
Copyright (C) 2018 The Journal of Minimally Invasive Surgery. All rights reserved.

\section{INTRODUCTION}

Single-incision laparoscopic surgery (SILS) for colorectal diseases has developed as an extension of standard laparoscopic minimally invasive procedures. Compared to the conventional laparoscopic surgery (CLS), the single-incision approach can enhance certain benefits of minimally invasive surgery, such as less blood loss, shortening of hospital stay, and faster recovery of bowel function. ${ }^{1,2}$

There are numerous reports regarding single-incision procedures and laparoscopic reoperations in colorectal disease. However, there are few reports about the role of repeat singleincision laparoscopic surgery (R-SILS) after the initial singleincision laparoscopic surgery.

Repeat SILS (R-SILS) represents an innovation; however, its adoption can be limited by technical challenges. Also, there 
Table 1. Baseline characteristics of 38 patients who underwent primarySILS

\begin{tabular}{|cc}
\hline \multicolumn{1}{|c}{ Clinical characteristics } & Value $(\mathrm{N}=38)$ \\
\hline Gender & \\
M & $21(55.3 \%)$ \\
F & $17(44.7 \%)$ \\
\hline Age (years) & $58.95( \pm 16.35)$ \\
\hline BMI $\left(\mathrm{kg} / \mathrm{m}^{2}\right)$ primary & $23.73( \pm 2.98) \mathrm{kg} / \mathrm{m}^{2}$ \\
\hline ASA stage & \\
I & $7(18.4 \%)$ \\
II & $30(79 \%)$ \\
III & $1(2.6 \%)$ \\
History of abdominal surgery & \\
Yes & $8(21 \%)$ \\
No & $30(79 \%)$ \\
\hline
\end{tabular}

is no sufficient data on its outcome. The selection of patients suitable for R-SILS, especially in those with a history of SILS, is still being evaluated. Technical challenges with SILS, such as greater difficulty exposing critical structures, more frequent instrument conflicts, and some issues with ease of camera operation and ergonomics, all potentially impose a disincentive toward wider adoption of its repetition. ${ }^{3}$ Furthermore, it is unclear whether the additional challenges associated with SILS can be balanced by the substantial improvements in length of hospital stay, time to resumption of postoperative diet, and time to complete recovery. Our main concern is whether RSILS exceeds the concept of a single incision and provides clinical benefits.

The purpose of this research is to analyze the results of RSILS and evaluate its applicability.

\section{MATERIALS AND METHODS}

This is a retrospective review of the prospectively collected SILS database in Samsung Medical Center, Seoul, Korea, between April 2009 and December 2015. Retrospective review of 38 patients who underwent R-SILS from 2207 patients who underwent primary SILS for colorectal diseases was performed. The surgeon decided whether to create a diverting ileostomy before making the incision considering the location of the mass, preoperative treatment history, and the patient's general condition. The initial incision was about $2 \sim 4 \mathrm{~cm}$ long, reflecting the patient's body shape and mass size. We used a custom-made glove port consisting of a surgical glove, a wound protector, and three or four Separator access systems. Unlike other ready-made ports for SILS, the trocars of this
Table 2. Reason for primary operation

\begin{tabular}{|lc|}
\hline \multicolumn{1}{|c|}{ Primary diagnosis } & Value $(\mathbf{N}=38)$ \\
\hline Cecal cancer & $2(5.3 \%)$ \\
\hline Ascending colon cancer & $6(15.8 \%)$ \\
\hline Transverse colon cancer & $3(7.9 \%)$ \\
\hline Sigmoid colon cancer & $4(10.5 \%)$ \\
\hline Rectosigmoid colon cancer & $4(10.5 \%)$ \\
\hline Rectal cancer & $13(34.2 \%)$ \\
\hline Others & $6(15.8 \%)$ \\
\hline
\end{tabular}

custom-made glove port do not intrude into the skin incision. This can reduce the collision between instruments. An additional port was inserted in case when it was difficult to proceed with the operation for any reason. The 12- $\mathrm{mm}$ trocar was mainly used. We used common straight devices for conventional laparoscopy in all cases.

Electronic medical records of the selected patients were thoroughly reviewed to obtain their demographic information, preceding interventions or re-interventions (radiological, endoscopic, and surgical), primary treatment characteristics, pre-operative imaging results, pathologic results, as well as the length of hospital stay and disease status at the last clinical follow-up.

For non-normal distributed data, the mean value is reported. All analyses were performed with IBM SPSS Statistics, version 22.0

\section{RESULTS}

From April 2009 to December 2015, 38 patients underwent repeat surgery via SILS. Patient characteristics are shown in Table 1.

There are various causes of primary surgery; among them, the most common was cancer (Table 2).

Therefore, bowel resection was performed as the most common primary surgery (Table 3).

The reasons for reoperation can be classified into three groups; 23 primary SILS-related complications (12 immediate, 11 delayed complications), Ileus was included for this reason of re-operation, it was in a condition requiring surgery due to continuation of ileus for more than two weeks and repeated hospitalization.10 cancer-related (4 metachronous, 6 recurrent colorectal cancers), and 5 other surgical indications (benign tumor, anal dysfunction, ischemic colitis, recurred pheochromocytoma, and ectopic pancreas) (Table 4).

Elective group is related to postoperative complications such as ventral hernia which do not require urgent treatment, 
Table 3. Type of primary operation

\begin{tabular}{|lc|}
\hline \multicolumn{1}{c}{ Operation } & Value $(\mathrm{N}=38)$ \\
\hline Right hemicolectomy & $8(21 \%)$ \\
\hline Left hemicolectomy & $2(5.3 \%)$ \\
\hline Anterior resection & $6(15.8 \%)$ \\
\hline Low anterior resection & $15(39.4 \%)$ \\
\hline Colostomy & $2(5.3 \%)$ \\
\hline Others $^{*}$ & $5(13.2 \%)$ \\
\hline
\end{tabular}

* Mass excision, total colectomy, exploration, TPC with IPAA, and transverse colectomy.

recurrence of cancer and diagnosis of new cancer. The postoperative interval was 546.3 days on average. The emergent group required urgent treatment like postoperative bleeding and anastomosis leakage, and it was often complication related to the first surgery. The interval after the first operation was 147 days on average, shorter than the elective group (Table 4).

Fecal diversion was the most common type of reoperation, seen in 11 cases. Of those, 10 were due to leakage. With regard to procedure details, 9 case of ileostomy, 1 case of endsigmoidostomy, and 1 colostomy due to anal dysfunction were performed (Table 4). Nine out of 11 diversion surgeries were performed through a single port, which was used later as the stoma site.

We used the same port sites in 29 patients. When selecting the port site in R-SILS, 22 patients from the elective group showed a tendency to use the previous port site more than the emergent group 7 patients.

There were 2 cases of conversion to an open or conventional method, all emergent group: 1 case to CLS due to poor visualization from severe bowel dilatation and 1 case to open surgery due to severe adhesion (Table 5). The Hospital length of stay was elective group at 7.3 days and emergent group at 14.9 days, requiring longer period at the emergent group.

Post-operative complications were found in $5(13 \%)$ of 38 R-SILS cases (1 Grade I, 1 Grade II, 2 Grade IIIa, 1 Grade IIIb complications). ${ }^{4}$ Ileus was reported in one patient, but improved with NPO and conservative treatment. Three patients developed complicated fluid collection, 2 of whom recovered with PCD drainage and antibiotics. The other patient recovered after surgery (irrigation \& drainage) and intensive antibiotic treatment for uncontrolled peritonitis, In 1 case, there was a suspected rectovesical fistula in the cystoscope after surgery, but it improved with maintained indwelling urinary catheter. There was no further abnormal finding in follow-up CT images (Table 6). There were 5 cases of primary SILS-related ventral hernia. However, there was no R-SILS-related ventral
Table 4. Repeat single-incision laparoscopic surgery type

\begin{tabular}{|c|c|c|c|}
\hline & $\begin{array}{l}\text { Elective } \\
(n=24)\end{array}$ & $\begin{array}{c}\text { Emergent } \\
(n=14)\end{array}$ & $p$ value ${ }^{*}$ \\
\hline Diagnosis & & & $<0.001$ \\
\hline Cancer related & $10(41.7)$ & $0(0.0)$ & \\
\hline Ventral hernia & $5(20.8)$ & $0(0.0)$ & \\
\hline lleus & $1(4.2)$ & $2(14.3)$ & \\
\hline Fistula & $2(8.3)$ & $0(0.0)$ & \\
\hline Leakage & $1(4.2)$ & $9(64.3)$ & \\
\hline Bleeding & $0(0.0)$ & $1(7.1)$ & \\
\hline Internal herniation & $0(0.0)$ & $1(7.1)$ & \\
\hline Ischemic colitis & $0(0.0)$ & $1(7.1)$ & \\
\hline Others ${ }^{\ddagger}$ & $5(20.8)$ & $0(0.0)$ & \\
\hline Operation name & & & $<0.001$ \\
\hline Hernia repair & $5(20.8)$ & $0(0.0)$ & \\
\hline Tumor excision & $3(12.5)$ & $0(0.0)$ & \\
\hline Anterior resection & 2 (8.3) & $0(0.0)$ & \\
\hline Low anterior resection & 2 (8.3) & $0(0.0)$ & \\
\hline Bowel resection \& anastomosis & $4(16.7)$ & $0(0.0)$ & \\
\hline Diversion & $2(8.3)$ & $9(64.3)$ & \\
\hline Hartmann op & $1(4.2)$ & $1(7.1)$ & \\
\hline Adhesiolysis & 1 (4.2) & $2(14.3)$ & \\
\hline Bleeding control & $0(0.0)$ & $1(7.1)$ & \\
\hline Internal herniation reduction & $0(0.0)$ & $1(7.1)$ & \\
\hline Others ${ }^{\S}$ & $4(16.7)$ & $0(0.0)$ & \\
\hline Interval (days) & 546.3 & 147.0 & $0.003^{\dagger}$ \\
\hline
\end{tabular}

Values in parentheses are percentages. ${ }^{*}$ Fisher's exact test, except for ${ }^{\dagger} t$ test. 'Benign tumor, anal dysfunction, recurred pheochromocytoma, s/p sig-

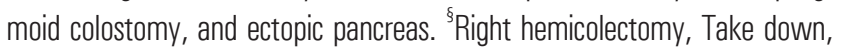
TEM with exploration, and Rectum pull-through.

hernia. There was no 30-day postoperative death related to RSILS.

\section{DISCUSSION}

Single-incision laparoscopic surgery (SILS) for colorectal surgery is now widely performed for various disease entities including malignant colorectal tumors. As surgeons become more comfortable with the techniques of SILS, patients with more complex surgical issues will undergo this procedure. Laparoscopic surgery can also be used during reoperation. ${ }^{5}$ Laparoscopic reoperation is feasible for the treatment of many 
Table 5. Intraoperative R-SILS outcomes

\begin{tabular}{lccc} 
& $\begin{array}{c}\text { Elective } \\
(\mathbf{n}=24)\end{array}$ & $\begin{array}{c}\text { Emergent } \\
(\mathbf{n}=14)\end{array}$ & $p$ value $^{*}$ \\
\hline $\begin{array}{l}\text { Single port site } \\
\quad \text { Previous }\end{array}$ & $22(91.7)$ & $7(50.0)$ & 0.006 \\
$\quad$ Stomy site & $2(8.3)$ & $7(50.0)$ & \\
$\begin{array}{l}\text { Conversion } \\
\quad \text { Conventional multi-port }\end{array}$ & $0(0.0)$ & $1(7.1)$ & \\
$\quad$ Open & $0(0.0)$ & $1(7.1)$ & \\
$\quad$ Not applicable & $24(100.0)$ & $12(85.7)$ & \\
Operation time (min) & $148.3 \pm 58.6$ & $119.2 \pm 70.9$ & $0.181^{\dagger}$ \\
EBL (ml) & $87.1 \pm 70.8$ & $135.7 \pm 129.8$ & $0.142^{\dagger}$ \\
\hline
\end{tabular}

Values in parentheses are percentages. ${ }^{*}$ Fisher's exact test, except for ${ }^{\dagger} t$ test. EBL = estimated blood loss.

Table 6. Postoperative complication (R-SILS)

\begin{tabular}{|c|c|c|c|c|}
\hline & \multicolumn{2}{|c|}{$\begin{array}{l}\text { Elective } \\
(n=24)\end{array}$} & $\begin{array}{c}\text { Emergent } \\
(n=14)\end{array}$ & $\begin{array}{c}p \\
\text { value }^{*}\end{array}$ \\
\hline None & 23 (95.8) & & $10(71.4)$ & \\
\hline \multicolumn{5}{|l|}{ Yes } \\
\hline $\begin{array}{l}\text { Complicated fluid } \\
\text { collection }\end{array}$ & 1 (4.2) & Grade III & 2 (14.3) Grade III & \\
\hline lleus & $0(0.0)$ & & 1 (7.1) Grade II & \\
\hline Rectovesical fistula & $0(0.0)$ & & 1 (7.1) Grade I & \\
\hline
\end{tabular}

Values in parentheses are percentages. ${ }^{*}$ Fisher's exact test $(p=0.072)$.

complications following major laparoscopic abdominal surgery. ${ }^{6}$ However, there is no report about the role of repeat single incision laparoscopic surgery (R-SILS). In this study, the purpose was to evaluate the feasibility of R-SILS. SILS has many advantages including a smaller incision, reduced pain and scarring, faster recovery, shorter hospitalization, and improved maintenance of abdominal wall integrity., ${ }^{1,2}$ Considering these advantages, a single incisional approach can be also used in reoperation in selective cases.?

Simple comparison of R-SILS results and SILS in other published studies, not only there was no significant difference in both morbidity and conversion rate, but average surgery time and bowel function recovery time showed similar to standard laparoscopic surgery. ${ }^{1,28}$ The postoperative mortality $0 \%$ and morbidity $13.2 \%$ of R-SILS are similar to mortality $0.28 \%$ and morbidity $13.2 \%$ in the Systemic review (Systematic review with meta-analysis of studies comparing single-
Table 7. Perioperative R-SILS outcomes

\begin{tabular}{lrrr} 
& $\begin{array}{c}\text { Elective } \\
(\mathbf{n}=24)\end{array}$ & $\begin{array}{c}\text { Emergent } \\
(\mathbf{n}=14)\end{array}$ & $p$ value* $^{*}$ \\
\hline Diet (POD\#) & & & \\
$\quad$ Gas out & $2.2 \pm 1.0$ & $1.8 \pm 1.5$ & 0.304 \\
SOW & $1.5 \pm 1.0$ & $2.4 \pm 1.9$ & 0.112 \\
SBD & $2.8 \pm 1.6$ & $5.3 \pm 2.8$ & 0.006 \\
Hospital length of stay (days) & $7.3 \pm 5.8$ & $14.9 \pm 9.5$ & 0.004 \\
\hline
\end{tabular}

Values in parentheses are percentages. ${ }^{*} \mathrm{~T}$ test. $\mathrm{POD}=$ postoperative date; SBD = semi-blended diet; SOW = sips of water.

incision laparoscopic colectomy and multiport laparoscopic colectomy) published in 2016. Also, there is no big difference compared with mortality $0 \%$ and morbidity $12 \%$ of the RCT (Randomized clinical trial of single-incision versus multiport laparoscopic colectomy) published in 2016. In this study, the morbidity over Grade III was $8 \%$ similar to $7.9 \%$ in RCT.

Comparing the conversion rate, multiport was $2.6 \%$ and laparotomy was $2.6 \%$ in this study, multiport was $4.5 \%$ and laparotomy was $1.4 \%$ in the Systemic review, there was no significant difference. The laparotomy conversion rate in the RCT was $1 \%$. Re-operation rate was $2.6 \%$, similar to $1.38 \%$ of the Systemic review and 3\% of the RCT.

Operation time was mean 137.9 min of R-SILS, mean Operation time was $147.28 \mathrm{~min}$ at the Systemic review, mean operation time was $156 \mathrm{~min}$ at the RCT. In this study, time to return of bowel function was an average 2.1 days, which was not much different from 1.96 days in the Systemic review.

EBL (estimated blood loss) was $105 \mathrm{ml}$ in R-SILS, $75.06 \mathrm{ml}$ in the systemic review and $21.4 \mathrm{ml}$ in the RCT. Comparing the Hospital length of stay, it was 10.1 days in the R-SILS, 5.55 days in the Systemic review, and 6 days in the RCT.

When we compared our results with other published studies, we were able to confirm similar results overall, except for EBL and Hospital length of stay. ${ }^{1,28}$

The length of hospital stay and EBL seemed to be quite increase in our study, probably due to complex conditions related to indication of R-SILS. In general, it is possible to take into consideration the difficult situation as reoperation itself and the delay in recovery after surgery (Table 7).

The rate of serious complications was low in our study, with only one anastomotic leak.

Given these results, R-SILS appears to be comparable to standard laparoscopy in terms of both safety and early postoperative clinical outcomes.

In our study, we performed 10 diverting ileostomies through the single port at the stoma marking site in the right lower 
quadrant for patients with anastomotic leakage after rectal surgery. It is useful to evaluate the anastomosis condition as well as suction of fecal materials without increasing wound complications.

SILS might be considered as the initial approach when loop ileostomy is planned to treat anastomotic leakage after rectal surgery.

Even though the initial approach started with a single port, additional trocar or conversion to the conventional multiport laparoscopic surgery should be considered if there is technical difficulty or a poor operative field. ${ }^{5.9}$ We converted to multiport laparoscopic surgery and open surgery due to massive adhesion and poor vision. It was difficult to use the previous post site in the emergent group, which is more relevant to postoperative complications requiring treatment, and food progression and extension of the hospitalization period were confirmed. It is considered that it is necessary to consider these points in the case selection for determining SILS during reoperation.

This study has several limitations. The number of cases of R-SILS was relatively small since this procedure was introduced recently and has been performed by few experienced surgeons. Additional time will be required to assess a larger number of patients for comparison to standard laparoscopy. This is a retrospective study; therefore, there is possibility of selection and information bias. However, we reviewed the medical records as well as prospectively collected SILS data from our center. Factors that we could not assess through the study might have affected our results. Therefore, future prospective studies with a larger sample size should provide evidence-based support for our current observations. Also, the $\mathrm{R}$-SILS in this study was performed by only one experienced surgeon at a single center. External validation of these results is needed, and incorporation of this technique into common surgical practice should be performed with caution.

In conclusion, this study reviewed the advantages of $\mathrm{R}-$ SILS such as reducing incisions, blood loss, length of hospital stay, and time of bowel function restoration. These procedures might improve some of the benefits of minimally invasive surgery with similar short-term clinical and surgical outcomes to the conventional colorectal surgery. We conclude that repeat single-incision laparoscopic surgery is a safe and feasible procedure in selected patients after initial single-port surgery by an experienced surgeon.

\section{REFERENCES}

1) Podda M, Saba A, Porru F, Pisanu A. Systematic review with meta-analysis of studies comparing single-incision laparoscopic colectomy and multiport laparoscopic colectomy. Surg Endosc 2016;30:4697-4720.

2) Markar SR, Wiggins T, Penna M, Paraskeva P. Single-incision versus conventional multiport laparoscopic colorectal surgerysystematic review and pooled analysis. J Gastrointest Surg 2014;18:2214-2227.

3) Ross H, Steele S, Whiteford M, et al. Early multi-institution experience with single-incision laparoscopic colectomy. Dis Colon Rectum 2011;54:187-192.

4) Dindo D, Demartines N, Clavien PA. Classification of surgical complications: a new proposal with evaluation in a cohort of 6336 patients and results of a survey. Ann Surg 2004;240:205-213.

5) Feigel A, Sylla P. Role of Minimally Invasive Surgery in the Reoperative Abdomen or Pelvis. Clin Colon Rectal Surg 2016;29:168-180

6) McCormick JT, Simmang CL. Reoperation following minimally invasive surgery: are the "rules" different? Clin Colon Rectal Surg 2006;19:217-222.

7) Arnell TD. Minimally Invasive Reoperation following Laparotomy. Clin Colon Rectal Surg 2006;19:223-227.

8) Watanabe J, Ota M, Fujii S, Suwa H, Ishibe A, Endo I. Randomized clinical trial of single-incision versus multiport laparoscopic colectomy. Br J Surg 2016;103:1276-1281.

9) Lu KC, Cone MM, Diggs BS, Rea JD, Herzig DO. Laparoscopic converted to open colectomy: predictors and outcomes from the Nationwide Inpatient Sample. Am J Surg 2011;201:634-639. 